\title{
Research on Identification of Flow Units Based on FZI
}

\author{
Ding $\mathrm{Yi}^{1}$, Guo Xiaobo ${ }^{1,2}$, Chang Shuyun ${ }^{1}$ \\ ${ }^{1}$ E\&D Research Institute of Daqing Oilfield, Hei Longjiang, 163712, PR China \\ ${ }^{2}$ College of Energy, Chengdu University of Technology, 610059, PR China
}

\begin{abstract}
The FZI expression is obtained by derivation, and the geological significance of FZI is proposed for the first time - it is a parameter reflecting the micro-pore structure of the rock, determined by the microstructure of the rock. Further analysis of FZI indicates that there are misconceptions in it, and it is feasible to identify flow units based on FZI. It points out the advantages and disadvantages of FZI. With the introduction of limited condition, better division of flow units can be realized based on FZI.
\end{abstract}

\section{Introduction}

People have different views on flow units ${ }^{[4 \sim 31]}$. In my opinion, flow units are firstly reservoir rocks, inside which have similar pore structure and petrophysical characteristics, and then come with flow characteristics and hydrodynamic characteristics. There are generally two ways of classification of flow units. The first one is outside-in ${ }^{[4 \sim 6]}$, which considers division of flow units should start with different barrier interfaces that affect fluid flow. Knowing the sizes of barrier interfaces, we find outer boundaries of flow units. Since fluid flow are blocked by barriers, flow units can be divided by identified barrier interfaces through structure analysis, from micro to macro. The second way directly starts from the carrier of flow units-reservoir [9 31], by determining conductivity and seepage capacity of sand body through qualitative-semiquantitative-quantitative method, flow units are identified and divided.

\section{FZI Derivation}

The main theoretical basis of K-C Equation is HagenPoisseuille's Law ${ }^{[1]}$ and Darcy's Law ${ }^{[1]}$, the concept of hydrodynamic radius ${ }^{[2]}$ has also been introduced.

Percolation property of rock depends on its microscopic pore-throat geometrical shape, that is, the mineral composition of rock (mineral type, content, morphology, position relative to pore-throat, etc.) and microstructure (grain size, rounding, sorting, filling, etc.). In despite of similar pore character, distinct rock units constitute through different permutations and combinations of rock properties. It is the rock units with similar hydrodynamic characteristics in the reservoir that determine the rock characteristics. Hydrodynamic radius is the link between hydraulic unit and porosity, permeability and capillary pressure. It is as shown below:

$$
r_{m h}=\frac{\text { Cross Section Area }}{\text { Wetted Perimeter }}=\frac{\text { Volume Open to Flow }}{\text { Wetted Surface Area }}
$$

For a circular, cylindrical capillary tube, $r_{m h}=r / 2$.

According to the hydrodynamic radius, Kozeny and Carmen treated the rocks in the reservoir as a capillary bundle (Fig. 1)

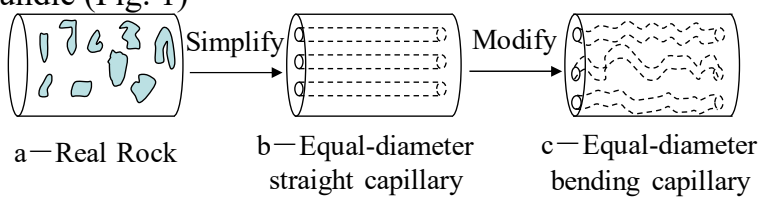

Fig. 1. Schematic diagram of Capillary Bundle Model

Fig 1c shows there is a difference between Le, which is the length of actual passage inside rock, and the apparent rock length L, thus the concept of tortuosity is introduced into the relationship

$$
\tau=L_{e} / L
$$

Define cross section area of the rock as A, radius of the capillary tube as $\mathrm{R}$, and there are $\mathrm{n}$ capillary tubes, then the specific surface $S_{g v}$ of the rock can be defined as

$$
S_{g v}=\frac{n A \cdot 2 \pi r \cdot L \tau}{A L}=n \pi r^{2} \tau \frac{2}{r}
$$

and effective porosity $\phi_{e}$ can be expressed as

$$
\phi_{e}=\frac{n A \pi r^{2} L \tau}{A L}=n \pi r^{2} \tau
$$

According to Hagen - Poisseuille's law

$$
Q=\frac{n A \cdot \pi r^{4} \Delta P}{8 \mu L \tau}
$$

By Darcy's law

$$
Q=\frac{K A \Delta P}{\mu L}
$$

According to the principle of equivalent seepage resistance, the following relationship can be obtained

$$
\frac{K A \Delta P}{\mu L}=\frac{n A \cdot \pi r^{4} \Delta P}{8 \mu L \tau}
$$

\footnotetext{
* Corresponding author: dingyi007@petrochina.com.cn
} 


$$
K=\frac{n \pi r^{4}}{8 \tau}=\frac{\left(n \pi r^{2} \cdot \tau\right) \cdot r^{2}}{8 \tau^{2}}
$$

Substitute Eq.4 into Eq.8, following relationship can be obtained

$$
k=\frac{\phi_{e} r^{2}}{8 \tau^{2}}=\frac{\phi_{e}}{2 \tau^{2}}\left(\frac{r}{2}\right)^{2}=\frac{\phi_{e} r_{m h}^{2}}{2 \tau^{2}}
$$

where $K$ is permeability in $\mu m^{2}, \phi_{e}$ is effective porosity in decimal, $r_{m h}$ is hydraulic radius in $\mu m$ and $\tau$ tortuosity of pore medium, dimensionless.

There are two premises for Eq.9: the flowing time (i.e., the velocity) of fluid in the rock is equal to that in the capillary bundle, that is to say, capillary bundle is the seepage equivalent model of rock; Porosity shall be effective porosity.

Assuming the rock volume is 1 , the effective pore volume is $\phi_{e}$, the particle volume should be $\left(1-\phi_{e}\right)$, and the surface area of unit particle volume is $S_{g v}$, thus the fluid volume passing through the rock is $\phi_{e}$, and the wetting surface area is $S_{g v}\left(1-\phi_{e}\right)$. Then Eq. 10 can be derived from Eq.1:

$$
r_{m h}=\frac{\phi_{e}}{S_{g v}\left(1-\phi_{e}\right)}
$$

where $S_{g v}$ is the surface area of unit particle volume in $\mu m^{-1}$, so Eq.11 can be derived from Eq.9 and Eq.10 as follows:

$$
k=\frac{\phi_{e} r_{m h}^{2}}{2 \tau^{2}}=\frac{\phi_{e}{ }^{3}}{\left(1-\phi_{e}\right)^{2}} \frac{1}{2 \tau^{2} S_{g v}^{2}}
$$

Substitute K-C into the relationship:

$$
k=\frac{\phi_{e}{ }^{3}}{\left(1-\phi_{e}\right)^{2}} \frac{1}{F_{s} \tau^{2} S_{g v}^{2}}
$$

Where FS is shape coefficient (cylinder is 2)

$F_{S} \tau$ is usually called Kozeny constant. It Is a constant within the same flow unit and varies between different flow units (between 5 and 100). It can be seen from the above derivation process that the $K-C$ equation corrects the cross section shape of the channel, so it describes the relationship between specific surface, permeability and porosity among rocks more truly.

Following relationship can be derived from Eq.12

$$
\sqrt{\frac{k}{\phi_{e}}}=\frac{\phi_{e}}{1-\phi_{e}} \frac{1}{\sqrt{F_{s}} \tau S_{g v}}
$$

The unit of permeability is still $\mu m^{2}$, then the following parameters can be defined:

Reservoir Quality Index RQI (in $\mu m$ )

$$
R Q I=\sqrt{\frac{k}{\phi_{e}}}
$$

Ratio of pore volume to particle volume (dimensionless)

$$
\phi_{Z}=\frac{\phi_{e}}{1-\phi_{e}}
$$

$$
F Z I=\frac{1}{\sqrt{F_{s}} \tau S_{g v}}=\frac{R Q I}{\phi_{Z}}
$$

It can be seen from Eq.16 that FZI, in a sense, is inversely proportional to the surface area of unit particle volume $\left(S_{g v}\right)$ and directly proportional to the volume of unit particle surface area, which further reflects the geological significance of this parameter -- the volume of unit particle surface area, and indirectly reflects the thickness of particles and the degree of skeleton dispersion.

The larger FZI is, the smaller $S_{g v}$ is, the coarser the particles of porous media are, the better degree of sorting is, the better degree of grinding is, and the smaller dispersion degree of the skeleton is. On the contrary, the smaller FZI is, the bigger $S_{g v}$ is, the finer the particles of porous media are, the worse degree of sorting is, the worse degree of grinding is, and the greater dispersion degree of the skeleton is.

Since different microscopic properties of these particles are corresponding to different sedimentary environments and diagenetic process, so different FZI is also corresponding to different sedimentary environments and diagenetic processes. Since skeleton surface of rock acts as a boundary of fluid flow, the permeability of rock and fluid absorbance on skeleton surface have important impacts on the interfacial phenomenon between rock and fluid, as well as the resistance to flow of fluid through rock.

\section{Clarification of the Hydraulic Units Identification Based on FZI}

This is a typical example of using quantitative methods to classify flow units. However, when applied in practice, people may think that the idea of using FZI to identify flow units is unreasonable due to lack of understanding or partial understanding of the method. In Amaefule's paper ${ }^{[20]}$, an oil field in Southeast Asia is divided into 5 categories, in which the porosity of type II flow unit ranges from 0.13 to 0.38 and the permeability ranges from $50 \mathrm{MD}$ to $3500 \mathrm{MD}$. Then, it is considered that rocks with a porosity of 0.13 and a permeability of 50md are classified as homogeneous with rocks with a porosity of 0.38 and a permeability of $3500 \mathrm{MD}$. That is to say, rocks with low-porosity and low-permeability are classified into the same class with rocks with highporosity and high-permeability by FZI classification. The following calculation shows that this understanding is wrong.

It should be noted that although pore permeability of type II flow unit divided by Amaefule varies in different ranges, there are four different pore permeability combinations (Table 1), and FZI of these four cases is calculated by Eq.9: 
Table1. FZI computation sheet

\begin{tabular}{|c|c|c|c|}
\hline FZI & Porosity & $\begin{array}{c}\text { Permeabilit } \\
\text { y md }\end{array}$ & Rock Type \\
\hline 4.12 & 0.13 & 50 & $\begin{array}{c}\text { Low porosity, } \\
\text { Low permeability }\end{array}$ \\
\hline 34.48 & 0.13 & 3500 & $\begin{array}{c}\text { Low porosity, } \\
\text { High permeability }\end{array}$ \\
\hline 0.59 & 0.38 & 50 & $\begin{array}{c}\text { High porosity, } \\
\text { Low permeability }\end{array}$ \\
\hline 4.92 & 0.38 & 3500 & $\begin{array}{c}\text { High porosity, } \\
\text { High permeability }\end{array}$ \\
\hline
\end{tabular}

It is clear from the table that the FZI of these four combinations are quite different. In other words, since FZI values of these four combinations differs greatly, it is impossible for the four combinations to be divided into the same flow unit. This also proves that FZI did not classify the four rock types, such as low porosity-low permeability and high porosity-high permeability, into the same flow unit.

\section{Further Analysis of FZI}

For better understanding of FZI, we should start with its definition. Let's take a further look at this part of Eq.16:

$$
F Z I=\frac{1}{\sqrt{F_{s}} \tau S_{g v}}
$$

Eq.17 shows that FZI is determined by Kozeny constant and $S_{g v}$. As long as the rock is determined, the Kozeny constant of the rock is fixed and $S_{g v}$ is determined as well. This indicates that FZI is a parameter reflecting the microscopic pore structural property of the rock itself (the geological significance of FZI mentioned above). Therefore, Eq.17 is actually the definition of FZI. In a sense, FZI, together with the petrophysical properties such as porosity and permeability, is a property of the rock itself. As long as the microscopic pore structure of the rock is determined, FZI is a fixed value and is not affected by other factors.

Let's move on to the other part of Eq.16

$$
F Z I=\frac{R Q I}{\phi_{Z}}
$$

According to the previous analysis, FZI is determined by the micro pore structure of the rock. That is to say, Eq.18 does not indicate that FZI is directly proportional to RQI and inversely proportional to $\phi_{Z}$. It can only be explained that when the reservoir rock microstructure FZI is fixed, RQI and $\phi_{Z}$ scale up or down in same proportion. So Eq. 18 cannot be the definition of FZI. Even with the same FZI, due to the different degree of compact arrangement and sorting of rock particles, the permeability and porosity change, which will lead to the change of RQI and $\phi_{Z}$ in proportion. The porosity changes from 0.01 to 0.3 , and
FZI changes from 0.5 to 7 . The permeability is calculated according to Eq.18, then we can generate the permeability - porosity -FZI diagram (Fig. 2).

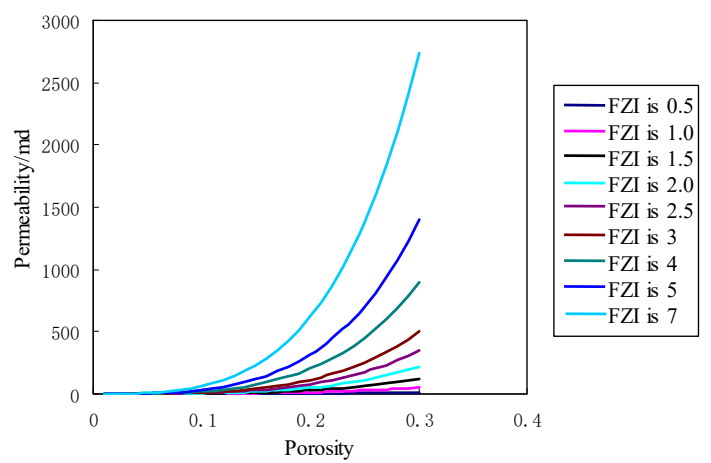

Fig. 2. Porosity-Permeability-FZI diagram

As can be seen from the figure, when porosity and permeability are small to a certain extent, FZI cannot be used as the basis for flow units identification. On the other hand, with certain low porosity and permeability (say porosity less than 0.15 and permeability less than $50 \mathrm{MD})^{[21]}$, the reservoir is considered as a low-porosity and low-permeability reservoir and there is no need for flow units identification. So, here, we set a threshold value with a porosity of 0.15 and a permeability of $50 \mathrm{md}$. For reservoir with porosity greater than 0.15 and permeability greater than 50md, flow units can be identified based on FZI.

In view of the difficulty in effectively distinguishing the FZI index of the reservoir flow units with low porosity and low permeability, further research can be carried out by subdividing the sedimentary facies type and rock type, combining with the pore throat structure and pore throat radius distribution study.

\section{Conclusions}

(1) The geological meaning of FZI is explained and the definition of FZI is clarified.

(2) Problems existing during flow units identification are analyzed based on FZI.

(3) Restrictive conditions are introduced to avoid the problem of dividing low-porosity and low-permeability reservoirs into the same type of flow units as highporosity and high-permeability reservoirs.

\section{References}

1. Kong Xiangyan, Advanced Mechanics of Fluids in Porous Media" [M], USTC Press, Hefei China, 1999:21-40

2. Bird, R.B.. Steware, W.E. and Lightfoot. E.N. Transport phenomena, New York, Wiley (1960) : 271-306.

3. He Gengsheng: "Petrophysics" [M]. Petroleum Industry Press, BeiJing, 2007: 7, 292-295.

4. Jiao Yangquan and $\mathrm{Li}$ Zhen: "Genesis and Distribution Regularity of Isolate Barrier Beds in 
Channel Reservoir Sandbody" [J], Petroleum Exploration and Development, 1995,22(4) : 78-91.

5. Yang Kun: "Practice and Understanding of Subdivision Production of IV4 Thick Oil Layer in the Northern Block of Shuang He Oilfield" [J], Petroleum Exploration and Development, 1997, 24(5): 80-82.

6. Zeng Daqian, Li Zhongchao: "Types of cyclic sequence and reservoir flow units in the Upper S3 formation in Pucheng Oilfield" $[\mathrm{J}]$, ACTA PETROLEI SINICA, 2002, 23(3): 39-42.

7. Liu Jiyu, Hao Jingbo and Yi Wanquan, etc: "Studying method and its significance of flow units" [J], JOURNAL OF DAQING PETROLEUM INSTITUTE, 1998, 21(1) : 5-7.

8. Hearn C L, Hobson J P and Fowler M L. Reservoir Characterization for Simulation, Hartzog Draw field, Wyoming.L.L.Lake, H.B.Carroll, Jr., eds.Aca-demic Press, 1984, 36(9):1335-1344.

9. Ebanks W J. The Flow Unit Concept - An Integrated Approach to Reservoir Description for Engineering Projects, AAPG. Annual Convention June, 1987,71(5):551-552.

10. Barr D C and Altunbay M. Idenyifying hydraulic units as an aid to quantifying depositional environments and diagentic facies, Geological Soc of MalaysiaSymp. on Reservoir Evaluation/formation Damage, Kuala Lumpur, July 11, 1992.

11. Ahr W M. Pore chatacteristics as surrogates for permeability in mapping reservoir flow units: Vaccum San Andres field Lea Country, New Mexico[J], AAPG Bulletin,1991,75(3):532-533.

12. Alden J. (Jeff) Martin, Stephen T. Solomon, Dan J. Hartmann. Characterization of Petrophysical Flow Units in Carbonate Reservoirs [J] . AAPG Bulletin, 1997,81(5): 734-759.

13. Testerman J. A statistical reservoir zonation technique. J PetroTech,1962,14 (5):889-893.

14. Cant D J. Subsurface facies analysis. In: Walker R G, James N P(eds.). Facies Models. Ontario: Geological Association of Canada, Love Printing Service Ltd,1992. 27-46.

15. Guangming ti,D.O. Obge ,Hatzignatiou D.G. Use of flow units as tool for reservoir description : A cas study[J]. SPE Fromation Evaluation,1995,10:122128.

16. Hearn C L, Ebanks W J Jr, Tye R S, et al. Geological factors influencing reservoir performance of the Hartwg Draw Field, Wgoming [J]. Journal of Petroleum Technology, 1984, 36:1335-1344.

17. Zhu Yushuang, Liu Yiqun and Zhao Jiyong, etc.: "A Study on the Microflow Characteristics of Different Flow Units" [J], Petroleum Geology and Experiment, 2008, 30(1): 103-107.
18. Lu Da: "The method of identifying and application of reservoir heterogeneity unit" [C], China University of Petroleum (East China), 2007: 16-23.

19. Wan Bingqian, Ma Yuming and Guo Xiaokun, etc.: " Research on Reservoir Flow Units" [J], Natural Gas Exploration and Development, 2008, 31(1): 5-8.

20. Amaefule J O. Altunbay M. Enhanced reservoir description: using core and $\log$ data to identify hydraulic (flow) units and predict permeability in uncored intervals/wells[A]. SPE 26436. 1993: 205220.

21. Wu Yuanyan, Wu Shenghe and Cai Zhengqi: Oil and Mineral Geology [M] , Bei Jing, Petroleum Industry Press, 2005: 176-177.

22. Bai Zhenqiang, Du Qinglong and Wang Shuguang, etc.: " Numerical simulation research on intrastratal flow unit in fluvial reservoir" [J], Petroleum Geology \& Oilfield Development in Da Qing, 2008, 27 (3): 55-58.

23. Lin Bo, Dai Junsheng and Lu Xianliang, etc.: " Prediction of Inter-Well Flow Units and Study on Distribution of Remaining Oil and Gas"[J], Natural Gas Industry, 2008, 27 (2) : 35-37.

24. Zhou Jianhua: " Research on Flow Units Division of Vlower Oil Group in Jianghe Area of Shuanghe Oilfield" [J], Journal of Xihua University (Natural Science Edition, 27(3): 8-11.

25. Xie Wei, Sun Wei and Wang Guohong: " Parameter Selection of Oil and Gas Reservoir in Flow Unit Division"[J], Journal of Northwest University (Natural Science Edition), 38(2).

26. Liu Jiangtao, Liao Dongliang and Ge Xinmin: " Water Phase Relative Permeability Calculation Based on Kozeny-Carman Equation " [J], Science Technology and Engineering, 2012, 12(29):75007504

27. Guo Xiaobo: " Calculation of average capillary pressure curve using hole volume ", [J], Journal of Central South University (Science and Technology), 2012, 43(11): 4514-4521.

28. Xu Peng, Qiu Shuxia, Jiang Zhouting and Jiang ying: "Fractal analysis of Kozeny-Carman constant in the homogenous porous media" [J], Journal of Chongqing University, 34(4): 78-82.

29. Zheng Bin and Li Juhua: "A New Fractal Permeability Model for Porous Media Based on Kozeny-Carman Equation" [J], Natural Gas Geoscience, 2015, 26(1):193-198.

30. Chen Peiyuan, Wang Xinglong and Guo Lina: "Complex pore structure geological modeling of carbonate reservoirs: a case of $\mathrm{M}$ formation of $\mathrm{B}$ oilfield in Missan Oilfields, Iraq" [J], Science Technology and Engineering, 2019, 19(11):81-89.

31. Aboozar Soleymanzadeh, Saeed Parvin, Shahin Kord: "Effect of overburden pressure on determination of reservoir rock types using RQI/FZI, FZI* and Winland methods in carbonate rocks" [J], Petroleum Science (2019)16:1403-1416. 